EUROPEAN JOURNAL OF ENVIRONMENT
European Journal of Environment and Public Health, 2018, 2(2), 07

ISSN: $2468-1997$

\title{
Environmental Characteristics Related to Comprehensive School Physical Activity Program Implementation
}

\author{
Ashley Phelps 1*, Hannah G. Calvert ${ }^{2}$, Jungyun Hwang ${ }^{3}$, Elizabeth Glowacki ${ }^{3}$, Russell L. Carson ${ }^{4}$, \\ Darla Castelli 1
}

${ }^{1}$ The University of Texas at Austin, 2109 San Jacinto Blvd, 78712 Austin, USA

${ }^{2}$ Boise State University, USA

${ }^{3}$ Northeastern University, USA

${ }^{4}$ University of Northern Colorado, USA

*Corresponding Author: ashley.phelps@utexas.edu

Citation: Phelps, A., Calvert, H. G., Hwang, J., Glowacki, E., Carson, R. L. and Castelli, D. (2018). Environmental Characteristics Related to Comprehensive School Physical Activity Program Implementation. European Journal of Environment and Public Health, 2(2), 07. https://doi.org/10.20897/ejeph/92007

Published: September 28, 2018

\begin{abstract}
This study examined environmental characteristics including demographic variables, facilities, and perceived support as contributors of Comprehensive School Physical Activity Program (CSPAP) implementation. Physical education teachers $(\mathrm{N}=306)$ from public, private, and other schools participated. The state of residence was the only demographic characteristic that predicted CSPAP implementation. Bike racks and total facilities were significant among facility predictors. Supportive administration and administrator's modeling physical activity (PA) also significantly contributed to CSPAP implementation. CSPAP implementation was highly associated with specific environmental characteristics that promote PA. These findings suggest that changes can be made to the school environment to facilitate PA opportunities.
\end{abstract}

Keywords: school environment, physical activity, active transportation, school administration

\section{INTRODUCTION}

An increase in physical activity among children is a core requirement for both the treatment and prevention of obesity (Cairney and Veldhuizen, 2017). According to the 2013 Youth Risk Behavior Survey, more than 70\% of youth failed to meet the national recommendations of engaging in at least 60 minutes of moderate to vigorous physical activity (MVPA) every day of the week (Kann et al., 2014). There are many potential reasons for this decrease, including a decline in the use of active transportation (Ross et al., 2017) increased screen time (Radesky and Christakis, 2016), and decreased physical education requirements in schools (Institute of Medicine [IOM], 2013).

This drop in children's physical activity (PA) is concerning for multiple reasons. PA has many known benefits for children, including improved cardiovascular health and fitness (Dietz et al., 2016), as well as enhanced cognitive functioning (Donnelly et al., 2017). Short bouts of PA have been shown to improve learning as well as behavioral outcomes in children, while long-term PA has been associated with improved academic achievement (Bustamante et al., 2017; Mahar et al., 2006). Conversely, sedentary behavior is detrimental to cardiovascular health and is associated with off-task behavior in school-aged children (Mahar et al., 2006; Carter et al., 2017; Grieco et al., 2016). Children who are less physically active in youth are also more likely to be physically inactive as adults (Telama 
et al., 2005) and develop chronic diseases (Picavet et al., 2017). These immediate and longitudinal health implications highlight the importance of establishing strategies to reduce sedentary time and increase PA behaviors early in life.

Children spend the majority of their time in school, thus making schools an ideal target for facilitating PA behaviors (Morton et al., 2016). To maximize this platform, a multi-component approach known as a Comprehensive School Physical Activity Program (CSPAP) may be implemented in hopes of achieving 60 minutes or more of PA throughout and beyond the school day (Centers for Disease Control and Prevention [CDC], 2015). A CSPAP includes five components: 1) quality physical education (QPE), 2) physical activity during school, 3) physical activity before/after school, 4) staff involvement, and 5) family and community engagement. Implementing a CSPAP has been recognized as an effective strategy for providing PA opportunities for children in school settings (IOM, 2013; Erwin et al., 2013). To enhance the utility of a CSPAP in a school, the elements affecting implementation must first be identified. Much of the research on CSPAP implementation to date has focused on the role of physical educators and classroom teachers in promoting student health and PA (Carson et al., 2014; Centeio and Castelli, 2013), while the effects of the school environment on CSPAP implementation remain unclear.

Previous research has shown that the characteristics of the school and neighborhood environments are related to the PA levels of children (Jansen et al., 2017). Within the school environment, higher levels of PA have been observed when recreational facilities such as fields, courts, and gymnasiums are available and adult-supervised (Harrison et al., 2016). In addition, schools that have a greater number of health and PA resources (e.g., health education, school breakfast programs, coordinated school health programs) also tend to have students who perform better academically (Ptomey et al., 2016). Active transportation to school, such as biking or walking, provides another outlet for children to be physically active before and after school. Aspects of the built environment, such as safe intersections and sidewalks on main roads are associated with higher rates of children using active transportation (Ding et al., 2011). Thus, schools need to be aware of how their facilities encourage or hinder engagement in PA during and outside of school hours.

All of these components fall within the CSPAP framework, making them appropriate targets for an intervention aimed at improving children's PA outcomes. Coupled with a school PA champion and supportive administration, facilities and resources contribute to the creation of a positive and welcoming PA environment that may influence the degree to which a CSPAP is implemented (Carson et al., 2014). Conversely, a school's ability to provide PA opportunities to children in an environment with few resources may be limited. The present investigation aimed to identify the modifiable and nonmodifiable aspects of the school environment associated with the successful implementation of a CSPAP in schools.

\section{METHODS}

The participants, instruments, procedures and data analysis are described. This study utilized a cross-sectional design based on first measures. School and teacher level variables across three different states, varying school types and educational levels were examined.

\section{Participants}

Upon Institutional Review Board approval for research, employed physical and health education teachers from several states throughout the U.S. were recruited based on in-state membership to professional associations. Physical education coordinators were also recruited. Each teacher had been invited to participate in a one-day professional development opportunity. The teachers $(\mathrm{N}=306)$ were from public $(\mathrm{n}=271,92.5 \%)$, private $(\mathrm{n}=16$, $5.5 \%$ ), and other $(\mathrm{n}=3,1 \%$ ) schools (urban, $18.8 \%$ and rural, $77.5 \%$ ) and voluntarily consented to participate in the research study prior to attending the workshop that focused on the implementation of a CSPAP in their school.

\section{Instrumentation}

CSPAP Index. The CSPAP index consisted of 136 items drawn from previously validated self-assessment surveys including the S-PAPA (Lounsbery et al., 2013) and the Physical Education Teachers' Physical Activity SelfEfficacy Instrument (Martin and Kulinna, 2003). The questions included information about the practices, policies, and resources available, as well as the degree to which some of the PA opportunities had already been implemented (e.g., running club, intramurals; Glowacki et al., 2016). Questions about the environment included what the teachers and students had access to within the school setting (e.g., a gymnasium, green space, blacktop area). Demographic characteristics of the school were also collected. Examples of demographic characteristic questions include, "How often does your school provide PE class to students?" and "How many minutes of PE do your children receive daily?" Additionally, questions were included about the teacher's perceptions of the administrative support, type and amount of professional development, and teacher incentives for promoting PA. Likert scale 
questions asking the degree to which you promote physical activity for each of the five CSPAP components were followed by an open-ended question requesting the teachers to provide evidence of his/her response. Evidence was provided in both a narrative explanation and supplied artifacts.

CSPAP Professional Development. The professional development provided the teachers with content knowledge, advocacy skills, and implementation approaches as they relate to a CSPAP. This CSPAP professional development was designed to help a teacher assume the role of a PA champion within their school. Following the training, each teacher was charged with assuming the role of PA champion. The training included implementing at least one of the five components of a CSPAP beyond the PA opportunities that already existed at their school (see Carson, 2012 and Centeio et al., 2014 for additional details about the professional development and its 14-month follow up). As part of the registration for the workshop, the teachers were asked to complete an online CSPAP Index, which was accessible through a password-protected website. The teachers completed the survey again at the end of the school year. Only data collected as part of the workshop registration were analyzed in this study; additional pre-test only analyses and pre-post test analyses can be found elsewhere (Carson et al., 2014; Glowacki et al., 2016). As part of the professional development, attendees were asked to submit artifacts that showcased the degree in which they implemented a CSPAP within their school.

Artifacts. A variety of collected artifacts confirmed the degree to which the new PA opportunity was implemented. Artifacts included, but were not limited to, lesson plans, meeting minutes about the program, program registration or enrollment, videos, pictures (e.g., a family fun night or school sponsored road race), and documentation of online PA breaks provided by classroom teachers. Each artifact was coded by type and evaluated by the research team to determine if the artifacts provided evidence of a new PA opportunity. Artifacts were also used to corroborate the CSPAP Index values.

\section{Data Analysis}

Data collected from the teachers in the CSPAP Index were downloaded from the online survey and statistical analyses were performed using SPSS version 22 (SPSS Inc., Chicago, USA). First, it was determined whether each dependent variable was normally distributed, by assessing its skewness and kurtosis. Descriptive statistics were used to represent characteristics of the participants and to confirm data entry. Missing data were coded as "- -999 " within the database. The total facilities variable was calculated by summing the positive responses to whether the teachers had access to a gymnasium, multipurpose room, blacktop area, grassy field, regular classroom for indoor PE, and trailer or portable building for indoor PE. The degree of implementation was calculated using a ratio variable of the number of new programs or programmatic changes divided by the five (the total number of components). Correlations were calculated across all of the variables. Multiple linear regressions were conducted to examine the relationship between environmental variables $(1$ - demographic characteristics, 2 - facilities, 3 perceived support) and degree of CSPAP implementation. Finally, in a separate analysis, hierarchical regressions were conducted to evaluate the contributions of previously entered predictors (modifiable vs. non-modifiable) on degree of CSPAP implementation for examining incremental validity. The multiple regression analysis was used to test if environmental variables significantly predicted the degree of CSPAP implementation. A post hoc analysis was conducted to evaluate the contribution of state of residence to degree of CSPAP implementation.

Of the 306 teachers who participated in the study, 33 were excluded because of lack of reporting on CSPAP implementation, and an additional 59 were excluded for not completing other portions of the CSPAP Index. A total of $214(70 \%)$ completed surveys were available for subsequent analyses. Sample characteristics are presented in Table 1.

\section{RESULTS}

\section{Predictor Variables on Degree of CSPAP Implementation}

In demographic characteristics, the model explained $18 \%$ of the variance $\left(\mathrm{R}^{2}=0.18, \mathrm{~F}_{6,215}=7.829, \mathrm{p}=0.001\right.$, see Table 2) and only state of residence strongly predicted degree of CSPAP implementation $(\beta=-0.36, \mathrm{p}=$ $0.001)$. In facilities, the model explained $13.2 \%$ of the variance $\left(\mathrm{R}^{2}=0.13, \mathrm{~F}_{7,290}=6.12, \mathrm{p}=0.001\right)$ and total sum of facilities $(\beta=0.116, \mathrm{p}=0.023)$ and bike racks $(\beta=0.25, \mathrm{p}=0.001)$ positively predicted degree of CSPAP implementation. Further, in perceived support, the model explained $23.6 \%$ of the variance $\left(\mathrm{R}^{2}=0.23, \mathrm{~F}_{5,293}=\right.$ 17.764, $\mathrm{p}=0.001)$ and supportive administration $(\beta=0.399, \mathrm{p}<0.001)$ and demonstration of PA among administration $(\beta=0.16, \mathrm{P}=0.003)$ positively predicted degree of CSPAP implementation. A post hoc analysis revealed that schools in Texas $(M=11.76)$ and Kansas $(M=11.18)$ were significantly more likely to be implementing CSPAP to a higher degree than schools in Louisiana $(M=9.62)$ and other $(M=9.64)$ states $(p<$ $0.05)$. 
Table 1. Demographic Characteristics

\begin{tabular}{|c|c|c|c|}
\hline & $\mathbf{N}(\%)$ & Mean & SD \\
\hline \multicolumn{4}{|l|}{ Participant Characteristics } \\
\hline \multicolumn{4}{|l|}{ Sex } \\
\hline Female & $215(73.4)$ & & \\
\hline \multicolumn{4}{|l|}{ Ethnicity } \\
\hline Caucasian American & $243(82.9)$ & & \\
\hline African American & $41(14)$ & & \\
\hline Hispanic American & $4(1.4)$ & & \\
\hline Other & $3(1)$ & & \\
\hline \multicolumn{4}{|l|}{ School Characteristics } \\
\hline \multicolumn{4}{|l|}{ Type of Institution } \\
\hline Public & $271(92.5)$ & & \\
\hline Private & $16(5.5)$ & & \\
\hline Other & $3(1.0)$ & & \\
\hline \multicolumn{4}{|l|}{ State } \\
\hline Texas & $49(16.7)$ & & \\
\hline Kansas & $65(22.2)$ & & \\
\hline Kentucky & $21(7.2)$ & & \\
\hline Louisiana & $137(46.8)$ & & \\
\hline Other & $21(7.2)$ & & \\
\hline \multicolumn{4}{|l|}{ Population Density } \\
\hline Rural & $227(77.5)$ & & \\
\hline Urban & $55(18.8)$ & & \\
\hline Percent of Students eligible for F/R Meals & & 62.9 & 29.14 \\
\hline Number of Students at the school & & 682 & 500.58 \\
\hline
\end{tabular}

Abbreviations: F/R, Free/Reduced

Table 2. Multiple Regressions of Variables on CSPAP Implementation

\begin{tabular}{|c|c|c|c|c|}
\hline Predictor & $\mathbf{R}^{2}$ & $\boldsymbol{B}$ & $t$ value & p-value \\
\hline Demographic characteristics & 0.18 & & & \\
\hline State & & -0.36 & -3.982 & 0.00 \\
\hline Region of the country & & 0.08 & 1.17 & 0.244 \\
\hline Rural/urban & & -0.07 & -0.74 & 0.46 \\
\hline Type of institution sponsoring your employment & & -0.104 & -1.63 & 0.105 \\
\hline Number of students at the school & & -0.03 & -0.42 & 0.67 \\
\hline Percent of Students eligible for F/R Meals & & -0.04 & -0.57 & 0.57 \\
\hline Facilities & 0.13 & & & \\
\hline Number of facilities available for PE classes & & 0.05 & 0.75 & 0.45 \\
\hline PA laboratory & & 0.04 & 0.75 & 0.45 \\
\hline PA equipment & & 0.01 & 0.18 & 0.86 \\
\hline Bike racks & & 0.25 & 4.42 & 0.00 \\
\hline Gym availability & & 0.02 & 0.41 & 0.68 \\
\hline Facilities & & 0.10 & 1.70 & 0.09 \\
\hline Total sum of facilities & & 0.16 & 2.29 & 0.02 \\
\hline Perceived support & 0.24 & & & \\
\hline Collaborations with Parks and Recreation departments & & 0.03 & 0.63 & 0.53 \\
\hline Collaborations with local businesses & & 0.04 & 0.64 & 0.52 \\
\hline Parent volunteers work in the CSPAP & & -0.02 & -0.40 & 0.69 \\
\hline Supportive administration & & 0.40 & 7.34 & 0.00 \\
\hline PA among Administration & & 0.16 & 2.96 & 0.00 \\
\hline
\end{tabular}

Abbreviations: PA, physical activity; PE, physical education; F/R, Free/Reduced

\section{Modifiable and Non-modifiable Predictors on Degree of CSPAP Implementation}

Table 3 shows the contributions of modifiable predictors (e.g., perceived support) and non-modifiable predictors (e.g... demographic characteristics, facilities) on the degree of CSPAP implementation. A hierarchical regression analysis revealed that non-modifiable variables in the first step and modifiable variables in second step significantly accounted for $27 \%\left(\mathrm{R}^{2}=0.27, \mathrm{~F}_{13,213}=5.671, \mathrm{p}<0.001\right)$ and $38 \%$ of the variance $\left(\mathrm{R}^{2}=0.38, \mathrm{~F}_{18,213}\right.$ $=6.672, \mathrm{p}<0.001)$. Particularly, facilities in non-modifiable variables $(\beta=0.229, \mathrm{p}=0.001)$ and supportive administration in modifiable variables $(\beta=0.30, \mathrm{p}<0.001)$ positively predicted degree of CSPAP implementation. 
European Journal of Environment and Public Health, 2(2), 07

Table 3. Hierarchical Regressions of Variables on CSPAP Implementation

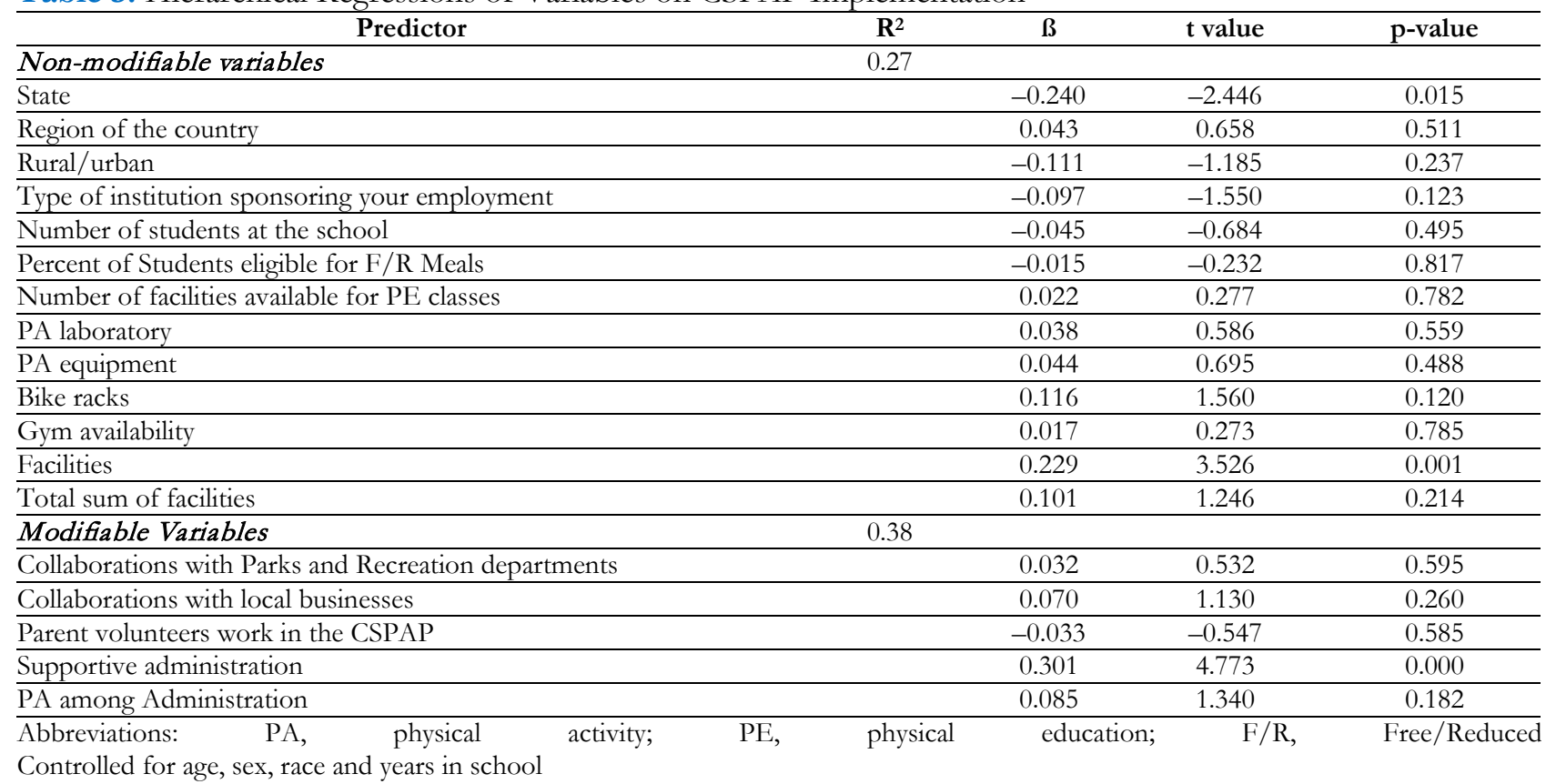

\section{DISCUSSION}

Given the findings from this study, environmental factors such as state policies, demographic characteristics, facilities, and perceived support from administration predicted the degree to which a CSPAP was implemented. First, state policies related to PE/PA can play a role in determining the degree to which a school can implement a CSPAP (CDC, 2015). This idea was supported by the fact that Texas, a state that mandates a coordinated school health model, which includes components of PA (Marx and Wooley, 1998), had teachers reporting higher degrees of CSPAP implementation at their schools. Furthermore, teachers in Texas addressed more components of the CSPAP, such as PA during the school day and active transportation. These initiatives were generated by the School Health Advisory committee (e.g., administrators, parents, teachers, and high school students).

Demographic characteristics such as population density of the school community, school size, and proportion of student body on free and reduced lunch did not significantly predict CSPAP implementation. This finding suggests that access to facilities, rather than school size or context, is more important for creating PA opportunities. Health professionals and health educators should be encouraged by these findings because making changes to the school environment is a more feasible task than making changes to school size and population density. These findings suggest that investing in playgrounds, a well-surfaced (perhaps painted) blacktop area, or green space may be more important than tailoring an intervention to specific demographic characteristics of a school.

The facilities that a school possesses were shown to contribute to the degree of CSPAP implementation in this study. The total number of facilities, which indicated how many different types of tangible PA resources a school had, was a significant predictor. Additionally, the presence of bike racks at school was a standalone predictor in the facilities regression model. This provides evidence that having resources, such as bike racks, which promote the use of active transportation, can have a significant influence on a school's ability to implement a CSPAP. Because the CSPAP framework encourages PA within and outside of the school day, having bike racks at schools may be one positive way to increase family and community involvement in children's PA. The mere presence of bike racks may prime students, teachers, administrative personnel, and family members to think about engaging in PA outside of school hours. Although this study suggests that an attitude of if we build it, they will come may be true, we do not believe that this action alone will be enough to sustain engagement; however, it does appear to ease the transition toward greater CSPAP implementation.

The level of perceived administrative support was also a predictor of implementation. The need for administrative support is not entirely surprising, given the fact that it is difficult for teachers to implement curricular changes such as adding PA minutes to the school day without support from the overseeing administration (Naylor et al., 2015). In the hierarchical regression model, these modifiable intrapersonal level variables accounted for $38 \%$ of the variance in the degree of CSPAP implementation, while non-modifiable variables accounted for $27 \%$. This finding reaffirms that while a school's demographic characteristics and facilities do influence CSPAP 
implementation, having PA champions who are supported by their administrators makes a large difference in a school's ability to implement a CSPAP (Deslatte and Carson, 2014)

To our knowledge, this is the first study examining the characteristics of a school environment on the implementation of a CSPAP. It is important to understand how a school environment facilitates or constrains a school's implementation of CSPAP since having an effective CSPAP in place leads to enhanced physical activity opportunities for children. The results of this study show that school location, the presence of more PA facilities, and greater levels of administrative support contribute to increased CSPAP implementation in schools. These findings parallel those from Brownson and colleagues (2001) who advocate for a combination of PA-friendly environmental factors in school communities along with increased social support (e.g., offering rides to sport practice) from friends, family, and community members.

\section{CONCLUSION}

There were both modifiable and non-modifiable environmental factors that were found to contribute to the degree of CSPAP implementation in this study. These results provide evidence for the importance of having a school environment that is conducive to fostering PA. These factors can be affected by the state in which a school is located, the demographic characteristics and facilities allocated for PA at the school, and the support given by school administration. It is encouraging that the most feasible modifiable factor of administrative support was also the strongest predictor of CSPAP implementation in this study. At the school level, the presence of a PA champion within the school, or a person who strives to create a community that is supportive of PA, can motivate school staff, teachers, administrators, and students to become more active. However, creating an environment conducive to PA also requires the support of parents and community members. Another point of contact within school communities is school organizations such as parent teacher associations and school health advisory committees. Individuals in these agencies can push for agendas that support PA, including fundraising for PE equipment, bike racks, playgrounds, blacktops, and green space. To gain administrative buy-in, it is important to emphasize how PA can enhance school academic performance rather than detract from time spent on other classroom subjects (Rasberry et al., 2015). All in all, the school environment can be conducive to the implementation of a CSPAP, especially when administrative support is at the forefront of these PA promotion efforts.

\section{Human Subjects Approval Statement}

This study was approved by the Institutional Review Board at Louisiana State University, IRB number E5703.

\section{Conflicts of Interest: None}

\section{REFERENCES}

Brownson, R. C., Baker, E. A., Housemann, R. A., Brennan, L. K. and Bacak, S. J. (2001). Environmental and Policy Determinants of Physical Activity in the United States. American Journal of Public Health, 91, 1995-2003. https://doi.org/10.2105/AJPH.91.12.1995

Bustamante, E. E., Williams, C. F. and Davis, C. L. (2017). Physical activity interventions for neurocognitive and academic performance in overweight and obese youth. Pediatric Clinics of North America, 63(3), 459-480. https://doi.org/10.1016/j.pcl.2016.02.004

Cairney, J. and Veldhuizen, S. (2017). Organized sport and physical activity participation and body mass index in children and youth: A longitudinal study. Preventive Medicine Reports, 6, 336-338. https://doi.org/10.1016/j.pmedr.2017.04.005

Carson, R. (2012). Certification and duties of a director of physical activity. Journal of Physical Education, Recreation, and Dance, 83, 16-29. https://doi.org/10.1080/07303084.2012.10598790

Carson, R. L., Castelli, D. M., Kuhn, A. C. P., Moore, J. B., Beets, M. W., Beighle, A., .., Glowacki, E. M. (2014). Impact of trained champions of comprehensive school physical activity programs on school physical activity offerings, youth physical activity and sedentary behaviors. Preventive Medicine, 69, S12-S19. https:// doi.org/10.1016/j.ypmed.2014.08.025

Castelli, D. M., Centeio, E. E., Hwang, J., Barcelona, J. M., Glowacki, E. M., Calvert, H. G. and Nicksic, H. M. (2014). VII. The history of physical activity and academic performance research: Informing the future. Monographs of the Society for Research in Child Development, 79(4), 119-148. https://doi.org/10.1111/mono.12133

Carter, S., Hartman, Y., Holder, S., Thijssen, D. H. and Hopkins, N. D. (2017). Sedentary behavior and cardiovascular disease risk. Exercise and Sport Sciences Reviews, 45(2), 80-86. https://doi.org/10.1249/JES.0000000000000106 
Centeio, E. E. and Castelli, D. M. (2013). Physical education teachers and comprehensive school physical activity programs. Research Quarterly for Exercise and Sport, 84, A36-A36.

Centeio, E. E., Erwin, H. and Castelli, D. M. (2014). Comprehensive school physical activity programs: Characteristics of trained teachers. Journal of Teaching in Physical Education, 33, 492-510. https://doi.org/10.1123/jtpe.2014-0066

Centers for Disease Control. (2015). Comprehensive school physical activity program (CSPAP). Available at: http://www.cdc.gov/healthyyouth/physicalactivity/cspap.htm

Elliot, E., Erwin, H., Hall, T. and Heidorn, B. (2013). Comprehensive school physical activity programs: Helping all students achieve 60 minutes of physical activity each day [Position Statement]. Journal of Physical Education, Recreation, and Dance, 84, 9-15. https://doi.org/10.1080/07303084.2013.838105

Deslatte, K. and Carson, R. L. (2014). Identifying the common characteristics of comprehensive school physical activity programs in Louisiana. Physical Educator, 71(4), 610.

Ding, D., Sallis, J. F., Kerr, J., Lee, S. and Rosenberg, D. E. (2011). Neighborhood environment and physical activity among youth a review. American Journal of Preventative Medicine, 41(4), 442-455. https://doi.org/10.1016/j.amepre.2011.06.036

Dietz, W. H., Brownson, R. C., Douglas, C. E., Dreyzehner, J. J., Goetzel, R. Z., Gortmaker, S. L., .., Story, M. (2016). Chronic disease prevention: Tobacco, physical activity, and nutrition for a healthy start. A vital direction for health and health care [Discussion Paper]. National Academy of Medicine, 1-14. https://doi.org/10.1001/jama.2016.14370

Donnelly, J. E., Hillman, C. H., Greene, J. L., Hansen, D. M., Gibson, C. A., .., Washburn, R. A. (2017). Physical activity and academic achievement across the curriculum: Results from a -year cluster-randomized trial. Preventive Medicine, 99, 140-145. https://doi.org/10.1016/j.ypmed.2017.02.006

Glowacki, E. M., Centeio, E. E., Van Dongen, D. J., Carson, R. L. and Castelli, D. M. (2016). Health promotion efforts as predictors of physical activity in schools: An application of the diffusion of innovations model. Joumal of School Health, 86(6), 399-406. https://doi.org/10.1111/josh.12390

Grieco, L. A., Jowers, E. M., Errisuriz, V. L. and Bartholomew, J. B. (2016). Physically active vs. sedentary academic lessons: A dose response study for elementary student time on task. Preventive Medicine, 89, 98-103. https://doi.org/10.1016/j.ypmed.2016.05.021

Harrison, F., van Slujis, E. M. F., Corder, K. and Jones, A. (2016). School grounds and physical activity: Associations at secondary schools, and over the transition from primary to secondary schools. Health \& Place, 39, 34-42. https://doi.org/10.1016/j.healthplace.2016.02.004

Institute of Medicine. (2013). Educating the student body: Taking physical activity and physical education to school. Washington: National Academies Press.

Jansen, F. M., Ettema, D. F., Kamphuis, C. B. M., Pierik, F. H. and Dijst, M. J. (2017). How do type and size of natural environment relate to physical activity behavior? Health and Place, 46, 73-81. https://doi.org/10.1016/j.healthplace.2017.05.005

Kann, L., Kinchen, S., Shanklin, S. L., Flint, K. H., Hawkins, J., Harris, W. A., .., and Whittle, L. (2014). Youth risk behavior surveillance-United States, 2013. Morbidity and Mortality Weekly Report, 63, SS1.

Lounsbery, M. A., McKenzie, T. L., Morrow Jr., J. R., Holt, K. A. and Budnar, R. G. (2013). School physical activity policy assessment. Journal of Physical Activity and Health, 10, 496-503. https://doi.org/10.1123/jpah.10.4.496

Mahar, M. T., Murphy, S. K., Rowe, D. A., Golden, J., Shields, A. T. and Raedeke, T. D. (2006). Effects of a classroom-based program on physical activity and on-task behavior. Medicine and Science in Sports and Exercise, 38(12), 2086. https:// doi.org/10.1249/01.mss.0000235359.16685.a3

Martin, J. J. and Kulinna, P. H. (2003). The development of a physical education teachers' physical activity selfefficacy instrument. Journal of Teaching in Physical Education, 22(2), 219-232. https://doi.org/10.1123/jtpe.22.2.219

Marx, E. E. and Wooley, S. F. E. (1998). Health is academic: A guide to coordinated school health programs. Teachers College Press.

Morton, K. L., Atkin, A. J., Corder, K., Suhrcke, M. and van Slujis, E. M. F. (2016). The school environment and adolescent physical activity and sedentary behavior: A mixed studies systematic review. Obesity Reviews, 17(2), 142-158. https:// doi.org/10.1111/obr.12352

Naylor, P. J., Nettlefold, L., Race, D., Hoy, C., Ashe, M. C., Higgins, J. W. and McKay, H. A. (2015). Implementation of school based physical activity interventions: A systematic review. Preventive Medicine, 72, 95115. https://doi.org/10.1016/j.ypmed.2014.12.034

Picavet, H. S. J., Blokstra, A., Spijkerman, A. M. W. and Verschuren, W. M. M. (2017). Cohort profile update: The Doetinchem cohort study 1987-2017: Lifestyle, health, and chronic diseases in a life course and ageing perspective. International Journal of Epidemiology, 0(0), 1-8. https://doi.org/10.1093/ije/dyx103 
Ptomey, L. T., Steger, F. L., Schubert, M. M., Lee, J., Willis, E. A., Sullivan, D. K., .., Donnelly, J. E. (2016). Breakfast intake and composition is associated with superior academic achievement in elementary school children. Journal of the American College of Nutrition, 35(4), 326-333. https://doi.org/10.1080/07315724.2015.1048381

Radesky, J. S. and Christakis, D. A. (2016). Increased screen time. Pediatric Clinics of North America, 63(5), 827-839. https://doi.org/10.1016/j.pcl.2016.06.006

Rasberry, C. N., Slade, S., Lohrmann, D. K. and Valois, R. F. (2015). Lessons learned from the whole child and coordinated school health approaches. Journal of School Health, 85(11), 759-765. https://doi.org/10.1111/josh.12307

Ross, A., Rodriguez, A. and Searle, M. (2017). Associations between the physical, sociocultural, and safety environments and active transportation to school. American Journal of Health Education, 48(3), 198-209. https://doi.org/10.1080/19325037.2017.1292877

Telama, R., Yang, X., Viikari, J., Valimaki, I., Wanne, O. and Raitakari, O. (2005). Physical activity from childhood to adulthood: A 21-year tracking study. American Journal of Preventative Medicine, 28(3), 267-273. https://doi.org/10.1016/j.amepre.2004.12.003 